\title{
Trial results of a hand-held applanation apparatus
}

\author{
H. P. B. WHITTY
}

London

Some results are presented of a recent trial of a hand-held portable applanation apparatus made to the specification of Prof. E. S. Perkins of the Institute of Ophthalmology, London.

A brief comparison was made with the Zeiss (Degenhardt) hand-held instrument. A small series of patients was examined, taking intraocular pressures with the hand applanator $\vec{\circ}$ while the patient lay flat, and then while the patient sat upright. Pressures were finally checked on the Goldmann applanation tonometer, used on the Haag-Streit slit lamp.

A brief outline of the apparatus is given below, but for full details, reference should be made to the original description by Perkins ( 1965 ).

\section{The apparatus}

Two alternative instruments were available, working either off a mains transformer, or off a dry $\overrightarrow{\mathscr{\Theta}}$ battery. The latter was chosen as the most easily portable and adaptable in all circumstances. $\subseteq$ The battery (Fig. I) was used constantly at 9 volts throughout. This illustration also shows that the tonometer has a rectangular handle containing a spring and counter weight activating a rod and collar into which is fitted a Goldmann applanation prism. Cobalt light is provided by a composite lamp and blue Perspex cone projecting up onto the tip of the prism.

The prism is backed by a magnifying viewing lens at the head of the apparatus, through which can be seen the normal fluorescein half-rings as seen with the Haag-Streit slit lamp at low magnification.

Above this is an adjustable rod-shaped head rest, controlled by a spring surrounding the front half of the rod in conjunction with a locking nut projecting from the top of the apparatus. The rod has a small plastic disc at the front and a plastic knob at the back.

Adjustment of pressure is made by digital operation of a disc, with a milled edge and circumferential pressure markings up to $50 \mathrm{~mm}$. $\mathrm{Hg}$, which is let into the back of the handle with the markings visible through an illuminated side-window. Pressures in grammes are indicated by divisions similar to those indicating $2 \mathrm{~mm}$. $\mathrm{Hg}$ per division on the Goldmann applanation tonometer.

During this trial, figures for the hand applanator have been recorded as $\mathrm{mm}$. $\mathrm{Hg}$ in view of the $\mathrm{O}$ agreement shown tonometrically and manometrically in the original trial.

\section{General observations}

A portable applanation tonometer, which can be used on patients both sitting and lying, is obviously useful in the following circumstances:

(A) IN HOSPITAL

(I) In eye out-patient departments for patients unable to sit at a slit lamp, because they are $\mathbb{\mathbb { D }}$ immobile in a wheel-chair, or lying on a trolley.

(2) For patients in bed, both those in eye wards and those immobilized in an orthopaedic traction apparatus such as a balkan beam.

(3) For patients in the operating theatre.

(4) For patients in casualty or other out-patient departments. 


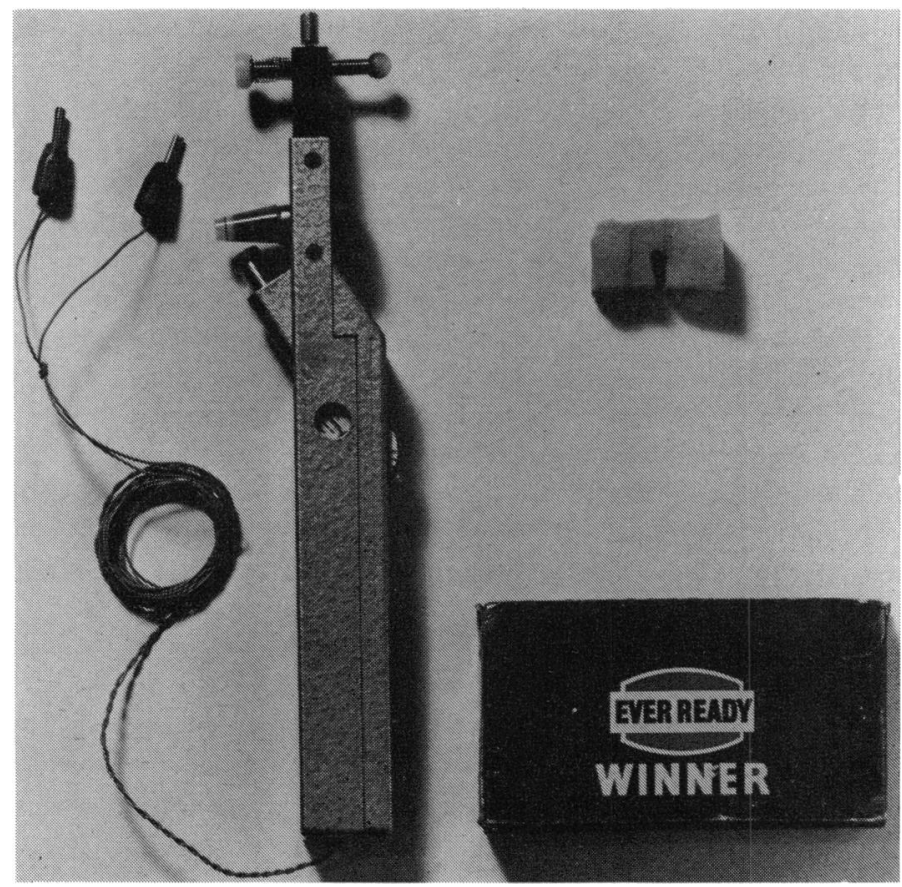

FIG. I Hand-held applanometer with battery and foam rubber to prevent head rest slipping on patient's forehead

(B) OUTSIDE HOSPITAL

(1) For occasional use in refraction clinics where it can reveal the need for a hospital visit.

(2) In domiciliary visits.

(3) As an alternative to the Haag-Streit slit lamp in private rooms.

\section{Method of use}

The procedure was first explained to the patient and his co-operation obtained. One or two drops of Amethocaine I per cent. were instilled into each eye, followed by a minimum of fluorescein 2 per cent. from a sterile glass rod. This was done to the right eye first, immediately before the pressure measurement was taken and then repeated with the left eye.

The front head rest disc was then placed on the patient's forehead and adjusted so that subsequent arc of rotation of the handle would bring the tip of the prism on the centre of the cornea. The applanation spring-pressure adjustment was then moved to near 20 to prevent vibration as with the Haag-Streit tonometer, and to reduce the time needed for adjustment of the pressure with the prism in contact with the cornea. The prism was placed momentarily in contact with the cornea each time and then removed a short distance. The patient was asked to confirm that nothing was felt. The prism was then lowered on to the cornea, the observer's eye positioned and pressure adjustments made. Readings were then taken as the applanation end-point was achieved.

The combined novesine and fluorescein drop was not used, as its availability when the hand applanator was used outside hospital was limited and the trial of a technique available under all circumstances was a principal aim. During the initial period of familiarization with the apparatus used at times outside hospital, fluorescein strips wetted with normal saline were used, touching the palpebral conjunctiva of the lower lid until a definite patch of stained conjunctival surface was visible. The amethocaine, always instilled first followed by the fluorescein when the stinging had ceased, reduced discomfort and enhanced confidence. 
From the start, it was found necessary always to use more fluorescein with the hand applanator, owing to the reduced illumination with the hand-held instrument.

As already noted during this trial, the right eye was examined first, and the left eye second. This $\vec{\Rightarrow}$ was originally due to the layout of the examination room having regard to maximum ease and speed $\stackrel{?}{\rightarrow}$ of examination. This was continued when checking pressures on the Goldmann applanation tonometer. A further constant pattern of examination was maintained by always using the hand $\overline{\bar{\omega}}$ applanator with the patient lying and then sitting, and finally going to the Haag-Streit instrument. $\mathbb{D}$

Pressure readings were recorded as the average of three, whatever the apparatus or the position of the patient. With a few patients, this normal procedure had to be reduced because of unsteadiness of the head, especially when the hand applanator was being used on a sitting patient.

All patients seen were taken from the clinic as subjects needing applanation tonometry presented. Almost all were patients diagnosed as cases of glaucoma and were adequately controlled by treatment. There was no discrimination as to age or sex, but the series did not include anyone either very old or remarkably young. In the case of the one patient showing a high pressure, the fact that the highest of reading did not exceed $50 \mathrm{~mm}$. $\mathrm{Hg}$ on the Haag-Streit instrument was quite fortuitous.

\section{Ease of handling and criticism}

The apparatus had been used initially with seated patients only, and some experience had therefore already been gained when this series of comparisons was started. At first, the reading had to be re-checked several times and difficulty was found placing the prism centrally on the cornea, but after adopting the technique of positioning the head rest and making preliminary contact with the cornea, central corneal contact was made more quickly and easily.

A constant source of difficulty and criticism of the apparatus was the weakness of illumination: with familiarization, difficulty in seeing the fluorescein half-rings was less but, where possible, all readings were taken in a darkened room. This could obviously

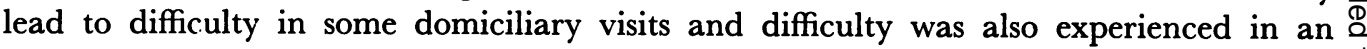
orthopaedic ward where readings were taken beside a window with no blinds. The $\overrightarrow{\overrightarrow{0}}$ similarity of the size of fluorescein half-rings to the Haag-Streit apparatus was found to be familiar and helpful.

All modifications in technique aimed at lessening the time of prism/corneal contact, as the patient had to maintain a steady head posture without a head rest to help, and the operator a steady hand and wrist. From this a tendency to take slightly low readings was found at first. There was a temptation to remove the prism before a proper make and break of half-ring contact was obtained, with the pressure almost always starting low and being raised to the correct end-point.

\section{Further methods adopted for increasing stability}

The observer's forehead was placed in contact with the ball on the back of the head rest N rod and a finger from the hand gripping the applanation handle was placed forwards on $\underset{\omega}{N}$ the patient's cheek.

A slight modification has been made to the head rest on the apparatus used. A $\frac{3}{4}$ inch

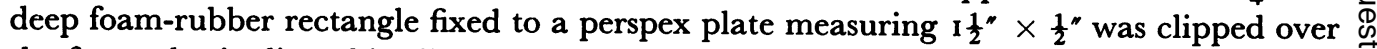
the front plastic disc; this allowed for tilting the apparatus without the head rest skidding sideways on the patient's forehead and was thought to be more comfortable for the patient if the observer leaned his forehead on the back of the head rest. The foam pad is shown separately in Fig. I.

Originally, for ease of manipulation of the pressure adjustment disc, it was thought that 
a looped hand-grip on the back of the handle, similar to a half-loop cupboard-door handle, would be an improvement. This was simulated for a time by the use of several large rubber bands. However, as familiarity with the apparatus progressed, this seemed less helpful and a slight loss of lateral stability of grip was noted; this modification was therefore abandoned.

\section{Brief comparison with the Degenhardt hand applanator}

This was made while initial familiarization with the Perkins hand applanator was proceeding. The Perkins apparatus was found to be lighter in weight than the Zeiss instrument and the illumination on the latter was obviously better, but the author found the superimposed brightly-lit pressure scale on the lower part of the applanation view dazzling and this was a source of difficulty.

\section{Comparative results}

32 patients were so compared as they presented in an Ophthalmic Out-patient Department. The results are given in Figs 2 to 7 (overleaf); there was a high degree of correlation between readings taken with the Perkins and Haag-Streit instruments. There was also a higher degree of correlation between readings with the hand applanator taken on patients sitting and lying.

The correlation coefficients are given in Table I. Little further comment is necessary, but it may be noted that degrees of correlation are high, all figures being near $\mathrm{I}$, while the figures for "Perkins (sitting)" $v$ "Perkins (lying)" are extremely high.

Table I Correlation coefficients between pressure measurements by different methods (32 subjects)

\begin{tabular}{|c|c|c|}
\hline Correlation & Right eye & Left eye \\
\hline $\begin{array}{ll}\text { Perkins (sitting) } & v . \text { Haag-Streit } \\
\text { Perkins (lying) } & v . \text { Haag-Streit } \\
\text { Perkins (sitting) } & v . \text { Perkins (lying) }\end{array}$ & $\begin{array}{l}\cdot 939 \\
\cdot 912 \\
\cdot 962\end{array}$ & $\begin{array}{l}\cdot 973 \\
\cdot 980 \\
\cdot 978\end{array}$ \\
\hline
\end{tabular}

The diagrams suggest that, particularly in the left eye, the hand applanator gives consistently lower figures than the Haag-Streit tonometer. This is true whether the patient is lying or sitting.

Table II (overleaf) shows that for both positions the difference is about I $\mathrm{mm}$. $\mathrm{Hg}$ for the right eye and for the left eye about ${ }_{1} \cdot 5 \mathrm{~mm}$. $\mathrm{Hg}$. All these differences are significant at the I per cent. level.

\section{Conclusion}

All readings taken with the hand applanator were found to be lower than those taken with the Haag-Streit tonometer. A difference of $\mathrm{I} \mathrm{mm}$. $\mathrm{Hg}$ and $\mathrm{I} \cdot 5 \mathrm{~mm} . \mathrm{Hg}$ (as shown in Table II) was thought to be acceptable.

There appeared to be no effect on the readings taken with the hand applanator whether the patients were lying or sitting. 

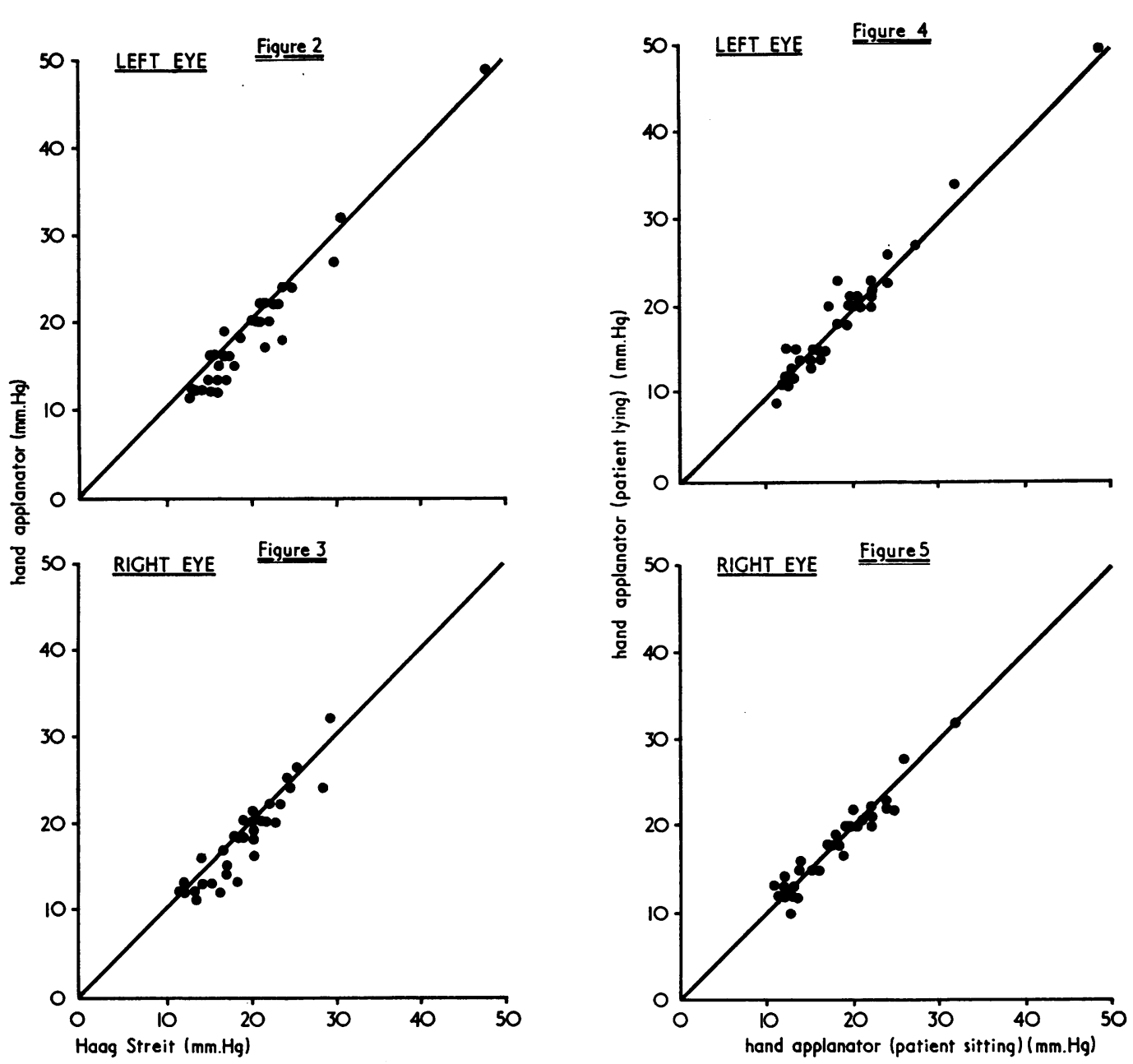

FIGS 2 and 3 Comparison of readings with Perkins hand applanator and Haag-Streit apparatus on the same patients sitting upright

FIGS 4 and 5 Comparison of readings with Perkins hand applanator on patients lying and then sitting

Table II Differences betuceen pressure $(\mathrm{mm} . \mathrm{Hg})$ in individual patients (Perkins applanator minus Haag-Streit). Means and standard errors

\begin{tabular}{|c|c|c|c|c|}
\hline Patient & Eye & Means \pm S.E. & $t$ & $P$ \\
\hline Lying & $\begin{array}{l}\text { right } \\
\text { left }\end{array}$ & $\begin{array}{l}0 \cdot 97 \pm 0 \cdot 34 \\
\mathrm{I} \cdot 4^{2} \pm 0 \cdot 33\end{array}$ & $\begin{array}{l}2 \cdot 84 \\
4 \cdot 36\end{array}$ & $\begin{array}{l}.01 \\
.001\end{array}$ \\
\hline Sitting & $\begin{array}{l}\text { right } \\
\text { left }\end{array}$ & $\begin{array}{l}0 \cdot 94 \pm 0 \cdot 29 \\
1 \cdot 52 \pm 0 \cdot 31\end{array}$ & $\begin{array}{l}3 \cdot 19 \\
4 \cdot 90\end{array}$ & $\begin{array}{l}\text {.OI } \\
\text {.0OI }\end{array}$ \\
\hline
\end{tabular}

A consistently lower reading with both instruments was noted when measuring the left eye compared to the right eye. This was commented upon in the recent Bedford Glaucoma Survey (Bankes, Perkins, Tsolakis, and Wright, 1968). 


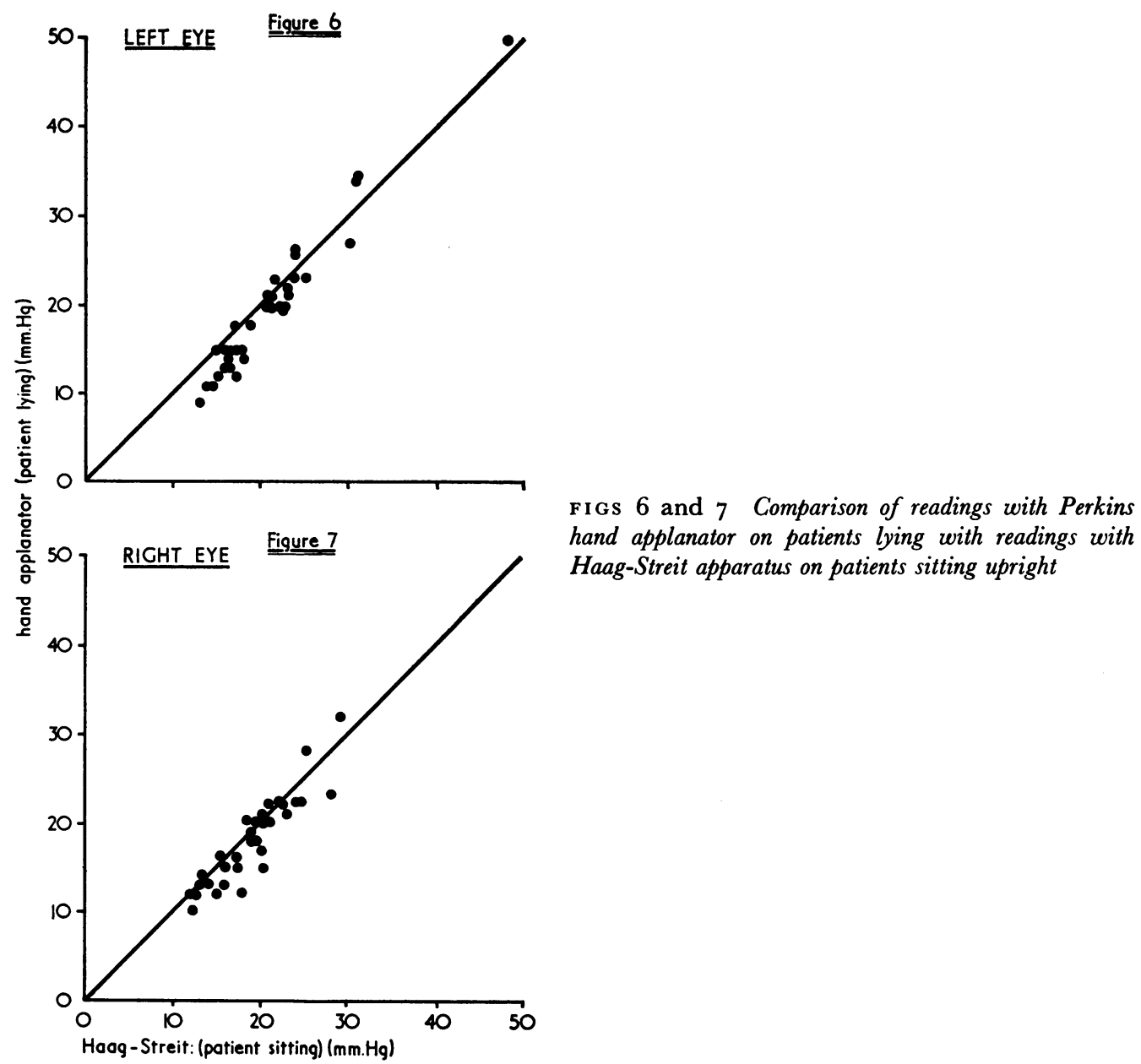

It is suggested that this pattern of slightly lowered readings overall for the second eye to be measured, in this series always the left eye, and of more markedly lowered figures for the hand-held apparatus as against the Haag-Streit tonometer, may merely indicate a slight defect in technique engendered by an underlying wish to reduce prism/corneal contact to a minimum of time leading to a fractionally premature cessation of the tonometry. Obviously this fault will disappear with further use and practice.

It is felt that, apart from poor illumination, the hand-held tonometer is a practical alternative to the Haag-Streit Goldmann applanation instrument.

I wish to acknowledge the encouragement received from Mr. C. A. G. Cook and Mr. J. R. Hudson, whose patients I was allowed to examine.

I also wish to acknowledge considerable help with the statistics from Mr. M. P. Curwen, statistician to the G.P. Research Unit, Guy's Hospital; to thank Mr. B. W. West and Clement Clarke Ltd. for providing the hand applanation apparatus, and to pay tribute to the late $\mathrm{Mr}$. Wagstaffe for advice given.

\section{References}

BANkes, J. L. K., PERkins, E. S., TSOlAKIS, s., and Wright, J. E. (1968) Brit. med. F., I, 79I

PERKINS, E. s. (1965) Brit. J. Ophthal., 49, 59 I 